\title{
Reflexões sobre os usos do espaço como garantia para a criação de meninos e meninas pequenas
}

\author{
Ingrid Hötte Ambrogi ${ }^{*}$
}

Resumo: Pensar a ação docente requer analisar as condiçôes objetivas nas quais elas ocorrem. O espaço das instituições escolares é um dos elementos de sustentação da práxis pedagógica e sua organização indica inúmeros elementos, tais como: coerência teórica e prática, condições objetivas para efetivar as propostas em relação ao número de crianças e o projeto pedagógico, entre outros. Portanto, quando se propõe a utilização de linguagens artísticas, os resultados das exploraçóes infantis vinculam-se à organização dos espaços em relação ao projeto a ser efetivado. Ana Lúcia Goulart de Faria, Mayumi W. Souza Lima, Rollo May e Ana Mae Barbosa são alguns dos autores que dão sustentação teórica para nossas reflexões e indicam que a preparação do espaço vinculado à proposta para a ação das crianças potencializa seu processo de experimentação de troca e gera satisfação diante de suas criações.

Palavras-chave: Arte na infância; organização do espaço físico; processo criativo.

\section{Reflections on the use of spaces as a guarantee for the little boys and girls' creations}

Abstract: Taking the teaching attitude into consideration requires an analysis of the objective conditions in which it occurs. The space is are one of the elements which sustain the pedagogical praxis and their organization indicates several elements, such as theoretical and practical coherence, objective conditions to foster the proposals as to the number of children and the pedagogical project, among others. Therefore, when we propose the use of artistic languages, the result of the children's projects is linked to the organization of the spaces in which these projects are performed. Ana Lúcia Goulart de Faria, Mayumi W. Souza Lima, Rollo May, Ana Mae Barbosa are some of the authors who give us the theoretical framework for our reflections and point out that the preparation of the places for the children's action enhances their process for experimenting exchanges and generates satisfaction to these children towards their creations.

Key words: arts in childhood; educational environment organization of the space; creative process.

* Professora do Programa de Pós-Graduação em Educação, Arte e História da Cultura da Universidade Presbiteriana Mackenzie, São Paulo, SP, Brasil. ihambrogi@yahoo.com.br 
Amai a infância; favorecei suas brincadeiras, seus prazeres, seu amável instinto.

Quem de vós não teve alguma vez saudade dessa época em que o riso está sempre nos lábios, e a alma está sempre

em paz?

J.J. Rousseau

Como seria, afinal, um espaço educacional promotor do ser humano, em especial para o fazer arte daquelas que iniciam sua jornada, as crianças, sobretudo as da primeira infância?

As ideias que sustentam a ação educativa e propõem a perspectiva de meninos e meninas ativos advêm de dogmas do século XIX e início do século XX, quando emergiram vários estudos e propostas vinculadas a uma concepção de educação em que a centralidade da ação educativa passa ser a criança e a sua forma de apreender. Podemos observar esses aspectos em princípios educativos desenvolvidos por Rousseau, Froebel, Montessori, Freinet, Dewey, entre outros, cujo vínculo essencial sinaliza a importância de dar espaço e vazão à criação e à expressão próprias da criança. Em todas essas abordagens, é privilegiada a ação, valorizando e promovendo essas iniciativas.

Igualmente, a concepção de espaço institucionalizado para o aprender passa a ser transformado a partir dessas propostas; o corpo necessita de espaço para agir, a movimentação das crianças pressupõe novos arranjos dos espaços que possibilitem outras formas de expressão.

Nas propostas educativas de Rousseau (2009), os espaços internos da casa e dos seus múltiplos ambientes e usos; e o externo, do campo, dos jardins e das hortas, são um convite para a exploração no longo percurso da educação até a fase adulta. Essa concepção passa a ser incorporada, de maneira institucionalizada, em outras propostas educativas posteriores, como Froebel (apud Formosinho; Kishimoto; Pinazza, 2007) em seu jardim de infância, cujo espaço é para ser explorado em atividades organizadas para as crianças pelas jardineiras, ou de maneira livre em alguns momentos pontuais preestabelecidos. Freinet (apud Elias; Sanches, 2007) mostra um espaço mais livre, múltiplo, repleto de trocas entre grupos de crianças durante as aulas passeio, entre outras propostas. Montessori (apud Araújo; Araújo, 2007) aprimora o uso dos espaços, adequando o tamanho dos móveis e dos utensílios ao tamanho das crianças, gerando autonomia para a manipulação dos materiais disponibilizados e a autogestão das atividades propostas e do tempo para realizá-las.

Cada um desses autores revela a ruptura com uma concepção tradicional de espaço educativo que, evocando Foucault, imobiliza os corpos infantis, doutrinando-os à obediência e à autorização para movimentar-se de uma forma regulada. 
Podemos considerar que o uso do espaço está vinculado à concepção de cultura de um momento histórico, no modo de conceber os espaços e os momentos para o aprender, estabelecendo que tipo de pessoas desejamos formar. A proposta de seus usos pode propiciar o adestrar ou o educar, o domesticar ou o formar para a autonomia.

A arquiteta Mayumi Souza Lima revela a relação intrínseca entre espaço e ambiente, entendendo que o espaço físico pode conter vários tipos de ambiente; dessa maneira, um mesmo espaço pode representar, para a criança, [...] "o espaçoalegria, o espaço-medo, o espaço-proteção, o espaço-mistério, o espaço-descoberta, enfim, os espaços da liberdade ou da opressão" (Lima, 1989, p. 30).

$\mathrm{O}$ espaço, nesse sentido, pode igualmente proporcionar à criança as múltiplas formas de expressão pelos usos de linguagens e suas formas de criação.

Picasso e Paul Klee, entre outros artistas de renome, apontam a singularidade da criação infantil desprovida de concepções predeterminadas, mas plenas de curiosidade e destemor pelo incerto.

Como revela Paul Klee no relato que segue: "Os quadros do meu pequeno Felix são com freqüência melhores que os meus, porquê os meus foram freqüentemente filtrados pelo cérebro" (apud Anning; Ring, 2009, p. 37).

Esse jogo da criança e suas formas de expressão vinculam-se com a brincadeira, o que pode ser traduzido como a busca pela livre expressão, pela possibilidade de testar sem compromisso com resultados, cujo horizonte é ilimitado de possibilidades. Essa liberdade de experimentação é um aspecto almejado pelos grandes artistas, que buscam novas composiçôes, muitas vezes apoiados na liberdade observada nas crianças em seu jogo e em sua brincadeira, expressões da criação livre das certezas.

Mas, e os espaços promotores dessas ações de liberdade, o que revelam? Eles potencializam, proporcionam às crianças, essencialmente, o que elas já trazem em si? Tornam possível a maneira de as crianças estarem inteiras no que fazem?

Há alguns anos me deparei com um pequeno texto cujo título era: "Mães e a interdisciplinaridade". Não se tratava de um texto acadêmico, mas de observações simples e cotidianas que revelavam o quanto esse espírito livre de mensuração e controle produz conhecimentos efetivos.

As mães, em seu cotidiano doméstico com seus filhos e outras crianças, quando proporcionavam a aproximação e a participação delas nas atividades cotidianas, ensinavam muito sobre o que é o mundo e sua cultura, sobre a forma de garantir bem-estar - como o lugar de dormir, a comida, a limpeza - e tudo isso nas mãos das crianças torna-se conhecimento.

Ao fazerem a comida e aproximarem seus filhos dessas tarefas, mostram como se lida com elementos como a água, o fogo, os alimentos e sua transformação, igualmente o cuidado em se relacionar com eles. Há uma garantia da regularidade 
dos eventos da vida cotidiana com a flexibilidade na tomada de decisões, o que é essencial para promoção do ato de conhecer. Podemos aproximar essas vivências daquelas que Rousseau (2009) descreve em seu livro Emílio durante parte da infância de seu pupilo idealizado.

Esses princípios norteadores entre o espaço institucional e o potencializar a expressão infantil devem observar como a criança se organiza, o que a favorece em termos de exploração e criação. Muitas vezes o espaço é organizado a partir de pressupostos que o adulto tem, sendo essa uma lógica que nem sempre favorece as crianças.

As questôes acima levantadas lembram o quanto o espaço para o aprender deve proporcionar experiências em que haja processos inteiros, sem a segmentação ou a burocratização do conhecimento.

Ana Lúcia Goulart de Faria (1999) traz, no capítulo intitulado "O espaço físico como um dos elementos fundamentais para uma Pedagogia da Educação Infantil”, a importância de garantir vivências significativas, usando água, fogo, terra, ar, em um ambiente promotor de descobertas para crianças e adultos.

Para efetivar essa proposta, a autora levanta uma centena de aspectos necessários para tornar o espaço educacional para a infância um espaço potencialmente gerador de experiências, aconchego e bem-estar geral para as crianças e para os adultos.

A possibilidade de um espaço agradável, em que os materiais possam ficar à disposição das crianças, em que a organização das atividades possibilite alternativas de agrupamentos e de atendimento às necessidades individuais e permita a manipulação desses materiais com diferentes propósitos, utilizando água, fogo, terra e ar, é fundamental em sua proposta.

Outro aspecto essencial refere-se à manutenção da limpeza, à organização e à coerência das atividades com os princípios educacionais que buscam a liberdade de expressão e de pensamento para as crianças; não apenas tarefas, atividades sem significado, mas construções efetivas, que demonstrem a singularidade de cada uma.

Esse universo é mostrado por Fortunati (2009) na descrição dos espaços educacionais para a infância, na Itália, onde essas dimensões são mostradas, discutidas e refletidas pelos profissionais da educação, pelos pais ou responsáveis e pela comunidade local.

Os espaços que são promotores de autonomia e descoberta devem ser projetados de maneira funcional, para, assim, gerar a organização das crianças e dos adultos que deles se utilizam.

Há, igualmente, que considerar os aspectos da legislação que regulamenta a metragem dos espaços para a instalação de uma unidade de educação infantil, garantindo as condições necessárias para o desenvolvimento de propostas singulares a essa faixa etária. No entanto, é preciso ressaltar que de nada vale apenas o 
espaço em si, mas o modo como se utiliza esse espaço é o que garante a essência do ambiente catalisador de experiências.

Uma das questôes que levantamos nesse sentido emerge dos postulados de Mayumi Lima de Souza (1989, p. 30) e diz respeito à cisão entre espaço e ambiente, como diz a autora: "[...] o espaço físico isolado do ambiente só existe na cabeça dos adultos". Para as crianças, estar no espaço é gerar um ambiente, é um estar no mundo.

Aprofundando a discussão, apoiamo-nos no conceito do geógrafo Milton Santos. Para ele, espaço é uma instância da sociedade que abarca os aspectos econômicos, político--institucionais e cultural-ideológicos, o que significa que cada um dos aspectos contém o espaço e é contido por ele.

Nesse sentido, o autor afirma:

Isso quer dizer que a essência do espaço é social. Nesse caso o espaço não pode ser apenas formado pelas coisas, os objetos geográficos, naturais e artificiais, cujo conjunto nos dá a Natureza. O espaço é tudo isso, mais a sociedade: cada fração da natureza abriga uma fração da sociedade atual. Assim, temos, paralelamente, de um lado, um conjunto de objetos geográficos distribuídos sobre um território, sua configuração geográfica ou sua configuração espacial e a maneira como esses objetos se dão aos nossos olhos, na sua continuidade visível, isto é, a passagem; de outro lado, o que dá vida a esses objetos, seu princípio ativo, isto é, todos os processos sociais representativos de uma sociedade em um dado momento. (Santos, 1985, p. 35.)

Portanto, o espaço destinado às ações educativas deve ser um espaço de vida, deve representar a sociedade, seu destino e sua representação social.

Dessa maneira, falar de espaço educativo é pensar em uma concepção de educação representada na materialidade do espaço e, especialmente, de seus usos. Para tanto, pensar sobre ele exige o conhecimento sobre os sujeitos que dele se utilizarão, suas finalidades e o tipo de concepção de formação de homem a que irá servir.

Nesse mesmo sentido, os espaços são reveladores dos projetos educativos que sustentam e da observação das dinâmicas proporcionadas. São indicadores da coerência entre a proposta educativa e a sua efetivação. Um exemplo é o que segue na apresentação das inquietações de um arquiteto escolar dos anos 1950; ainda que ele pense em construções escolares, vale a sua reflexão.

Hélio Queiroz Duarte, arquiteto de espaços escolares, que trabalhou com Anísio Teixeira, em artigo publicado na Revista Habitat, fez várias consideraçóes sobre a arquitetura escolar, das quais salientamos as seguintes: 
Escolas não podem ser desenhadas por qualquer um; não devem ser adaptações de exemplos estrangeiros; necessitam, sim, ser a expressão vivida da nossa maneira de ver, educacionalmente falando, e executadas com materiais locais.

Edifícios escolares valem pela flexibilidade que possuem no atendimento à dinâmica do ensino que se não pode comprazer em recintos numerados, catalogados e fechados, como peças de um museu de cera.

A mobilidade infantil - outra constante a ser levada em consideração em um bom projeto.

Toda escola deveria ter uma "matinha" e um "laguinho". Natureza e criança estão em correspondência biunívoca.

Necessita-se, sobretudo, levantar todos os índices biofísicos das crianças. Depois aplicá-los.

$\mathrm{O}$ empirismo e o descaso com que se projeta necessitam ser terminados. Cavalos e porcos têm mais técnicos que zelam pela sua integridade física do que as crianças. Por quê?

A persistir essa situação - continuaremos a construir prédios caros para uma instrução de "faz de conta". (Duarte, 1956, p. 237.)

Essas reflexóes revelam princípios e uma atitude em busca de proporcionar às crianças múltiplos espaços para o seu desenvolvimento, usando os espaços internos e externos, explorando as suas possibilidades criativas.

Márcia Carvalho e Mara Rubiano (1994) sinalizam as possibilidades de organização do espaço educativo para educação infantil conceituando espaços abertos, semiabertos e fechados, e os princípios desencadeadores dos mesmos. Cada uma das possibilidades tem em si uma estrutura, pois ora integra as crianças em grupos maiores ora permite certa privacidade. Para Carvalho e Rubiano, no arranjo aberto não há barreiras de objetos, e as crianças podem circular livremente, o que lhes proporciona vários deslocamentos. Já os arranjos semiabertos proporcionam à criança uma visão do todo e de todos os presentes, das outras crianças e do adulto das zonas circunscritas, propiciando agrupamentos entre elas. Já no arranjo fechado, há a presença de barreiras físicas, o que impede a visão de todas as áreas, dividindo o local; geralmente, segundo as autoras, as crianças permanecem em volta do adulto.

Podemos considerar, portanto, que a partir do que se tenha por objetivo em uma ação educativa, a configuração do espaço será um aliado para o sucesso da proposta, ou um impeditivo para que ela ocorra de forma adequada.

Além da preocupação com a disposição dos objetos em propostas de espaços, há a necessidade de o mobiliário ter características que possibilitem a autonomia das crianças; portanto, as mesas e as cadeiras devem ter tamanho adequado e devem 
ser em número suficiente para que elas possam utilizar, quando a proposta assim exigir, mesas e cadeiras e materiais diversificados e acessíveis para composição de suas obras.

No entanto, não devemos apenas falar das salas, mas do conjunto de espaços que as instituições de educação infantil devem possuir e devem igualmente possibilitar à criança explorar.

As atividades programadas em artes podem desenvolver etapas de construção em que as crianças possam, por exemplo, recolher material nas áreas externas para juntar aos materiais existentes nas salas e ou ateliês. Dessa forma, podem buscar e experimentar novas maneiras de produzir suas obras, desenvolver a percepção em distintos ambientes e reconhecer suas possibilidades. É nesse sentido que o espaço se torna ambiente, nos usos e na posse das crianças e dos adultos que nele convivem.

O espaço fantasia, o que gera novas ideias, descobertas, prazeres, risos de intensa felicidade, pode ser reconhecido em um espaço de posse, explorado de maneira segura, dinâmica, com propostas educativas coerentes.

Podemos alertar igualmente para a escolarização dos materiais disponibilizados para o fazer arte das crianças. Não é necessário utilizar apenas materiais industrializados, de uma maneira única; o interessante é fazer a adequação de vários tipos de suportes e objetos. Igualmente, há o alerta para que se tenha cuidado com a toxidade e o perigo na manipulação daqueles que exigirem uma maior atenção e organização para serem usados. É sempre interessante manipular todas as texturas de papéis possíveis, a viscosidade de diferentes tintas, tecidos, grãos, terra, areia; colorir objetos com anilinas comestíveis ou extratos de frutas e verduras, carvão, cacos de tijolo, enfim, usar o bom senso e a criatividade.

Muitas vezes, as informações que ampliam a possibilidade de exploração das artes para a infância não estão em publicações direcionadas à educação, há informações preciosas em ediçôes destinadas a artesanato e culinária, entre outras.

Uma experiência interessante foi desencadeada pela escola de arte Bauhaus, que, embora não sendo vinculada ao universo infantil, vale a pena ser evocada pela forma como abriu a possibilidade de exploração das linguagens artísticas de maneira próxima e experimental. São lições de vida que a Bauhaus trouxe em suas reflexões; são válidas para pensar outros universos da infância, seus olhares, e como podemos alimentá-los.

A concepção estética e de arte vinculada ao cotidiano de todos pode ser identificada com o movimento desse grupo alemão, que iniciou sua ação pedagógica com a educação de adultos. Entre 1919 e 1928, impregnou com suas ideias movimentos posteriores nas artes em geral, na arquitetura e na educação artística desenvolvida em escolas, além de outros segmentos expressivos. 
Um dos mestres da Bauhaus, Moholy-Nagy afirmou:

Todo mundo está equipado pela natureza para receber e assimilar experiências sensoriais. Todo mundo é sensível aos tons e cores, tem tato seguro e reage ao espaço etc. Isso significa que, por natureza, cada um é capaz de participar de todos os prazeres das experiências sensoriais, que qualquer homem sadio, pode também tornar-se um musicista, pintor, escultor, arquiteto, do mesmo modo que quando fala ele é um orador. (apud Silveira, 1973, p. 246.)

Esse movimento contagia e alarga a concepção de habilidade manual pura e simples para uma habilidade mais refinada, que consiste em desenvolver a consciência entre mente, olho e mão, o que pode, segundo seus integrantes, revelar as desarmonias do mundo e uma maior acuidade estética.

Dessa forma, proporcionar a expressão com as linguagens artísticas, especialmente as plásticas, nos espaços educativos para a infância, deveria desencadear a experiência de usar materiais de diversas naturezas para a criação livre. Cada dia poderia ser proposta a exploração de um material diferente em conjunto com outros conhecidos, como já mencionamos.

Essa experimentação evoca os postulados de Pierce:

[...] o artista seleciona elementos e sistemas visuais, combina materiais e procedimentos técnicos, elabora - no campo da obra de arte - significaçóes capazes de intervir na cultura E, no coletivo, propicia descobertas: a criatividade humana, dirigida à experiência de linguagem, dispóe-se ao conhecimento mais geral, compartilhado. (Rizolli, 2005, p.172).

Essa abordagem poderia fazer parte das propostas no interior das instituições de educação infantil, proporcionando a chance da escolha refletida, seja inicialmente pelo fazer empírico desencadeado pela própria experimentação dos materiais disponíveis, seja pelo aprofundamento de um projeto, com a pesquisa de formas e expressões artísticas.

Cabe ressaltar, como sinalizado por Ana Mae Barbosa (2001) em alusão a Dewey, que o simples contato com o material não promove uma ação estruturada; no entanto, é função do professor dimensionar inicialmente algumas possibilidades e respaldar as transgressões em novas propostas.

É pela interação com o outro que podem ser forjadas capacidades que vão sendo internalizadas com base em seu repertório; assim, a criança é capaz de formular novas possibilidades combinatórias, como revela Ferreira (1998): "Na relação com o "outro", a criança aprende. O desenho do outro pode impulsionar o seu desenho e, na inter-relação, a figuração pode transformar-se”. (Ferreira, 1998, p. 52). 
Despe-se, portanto, do conceito de patamares evolutivos do desenho e da criação. Em contraponto, Santaella (1995) sinaliza que os estudos das produções de sociedades primitivas revelaram que estas produzem formas diferentes de arte daquelas que a herança ocidental nos legou, mas não deixa de ser arte. Igualmente, as crianças produzem sua arte e seus significados, que não necessitam de padronização ou mensuração sobre fases a serem alcançadas.

Márcia Gobbi (2002), no artigo intitulado "O desenho da criança pequena, distintas abordagens na produção acadêmica em diálogo com a educação", disseca as muitas teorias que vêm ao longo dos anos tentando compreender o desenho infantil. Algumas dessas teorias difundiram no Brasil a ideia de patamares evolutivos e impregnaram as práticas educativas calcadas no desenvolvimento esperado, com resultados observáveis. Essa reflexão sobre uma gama de diferentes teorias propicia o questionamento sobre quais bases teóricas alicerçam as práticas para a promoção da criança e suas formas de expressão.

$\mathrm{Na}$ medida em que há o desafio de as crianças desenharem e analisarem suas produçôes e seus desejos, há o desafio em representar não só o figurativo, mas as sensaçōes, as emoçóes que transcendem a arte pronta, compactada, rígida, para torná-la uma expressão genuína daqueles que a produzem sob suas prerrogativas.

Ana Mae Barbosa (1984) comenta a respeito da experiência que julgou a mais importante no campo da educação através da arte, a de Josef Albers no Black Mountain Colege da Universidade de Yale, em que se conciliou uma filosofia educacional estruturada com a improvisação, possibilitando, segundo ela, o equilíbrio entre o caos e a ordem. Ideais advindos da emblemática escola já citada, Bauhaus, na qual Albers foi aluno e professor de e com Herbert Read. Essa experiência vigora como norte não só no ensino das artes nos EUA, mas em outras áreas e países.

Outra contribuição é a de Rollo May (1982), que propõe a coragem criativa com a possibilidade de subverter a paralisia em que se encontra, em especial, a educação. Segundo o autor, "[...] sem dúvida o magistério, [...], passa por mudanças radicais e precisa de indivíduos corajosos que valorizem e dirijam essas mudanças" [...] "A necessidade de coragem criativa é proporcional ao grau de mudança." (May, 1982, p. 19).

Nesse sentido, como afirma Barbosa (2001), a arte é aguçadora de sentidos e pode transmitir conceitos que outras linguagens discursivas e científicas não podem.

Portanto, cabe pensar como desencadear o processo criativo na escola, seja para as crianças pequenas, seja para as crianças maiores; a liberdade interna do ato de criação é uma experiência única, como reiterado por May (1982).

Buscamos por um espaço que promova - antes de levantar a bandeira por uma área do conhecimento - o ser humano, que deve integrar a ciência que foi capaz de desenvolver durante centenas de anos, e que o tornou mais humano. Dessa forma, 
ao buscarmos pela humanização do homem, somos capazes de remover fronteiras políticas, étnicas, sociais, e de respeitar o ser humano em sua integridade, para torná-lo mais homem.

Não podemos pensar, igualmente, nas linguagens de expressão das crianças sem pensar onde elas acontecem e o quanto o lugar abre ou fecha as possibilidades de efetivá-las.

A intenção deste artigo foi a de provocar inquietação e desencadear formas de pensar o espaço para a expressão da criança; não há fórmulas, acreditamos que a questão norteadora seja manter a coerência de uma proposta que garanta à criança criar, expressar-se, sentir-se acolhida, respeitada e feliz.

Em alusão a esse aspecto, ressaltamos a experiência italiana da cidade de Reggio Emilia, que busca um lugar de expressão para as infinitas linguagens da criança, inicialmente cem, depois muitas outras cem, pois a liberdade de pensamento é prenhe de criação.

\section{Referências bibliográficas}

ANNING, A.; RING K. Os significados dos desenhos de crianças. Porto Alegre: Artmed, 2009.

ARAÚJO, J. M.; ARAÚJO, A. F. Maria Montessori: infância, educação e paz. In: FORMOSINHO, J. O.; KISHIMOTO, T. M.; PINAZZA, M. Pedagogia(s) da infância: dialogando com o passado construindo o futuro. Porto Alegre: Artmed, 2007.

BARBOSA, A. M. Teoria e prática da Educação Artística. São Paulo: Cultrix, 1984.

BARBOSA, A. M. (Org.) Arte-educação: leitura no sub-solo. São Paulo: Cortez , 1997.

BARBOSA, A. M. John Dewey e o ensino de arte no Brasil. São Paulo: Cortez , 2001.

CARVALHO, M. I.; RUBIANO, M. R. B. Organização do espaço em instituições préescolares. In: OLIVEIRA, Z. M. R. (Org.). Educação Infantil: muitos olhares. São Paulo: Cortez, 1994.

DUARTE, H. Considerações sobre arquitetura e educação. Acrópole, São Paulo, abr. 1956.

EDWARDS, C.; GANDINI, L.; FORMAN, G. (Org.). As cem linguagens da criança: a abordagem de Reggio Emilia na educação da primeira infância. Porto Alegre: ArtMed, 1999.

ELIAS, M. DEL. C.; SANCHES, E. C. Freinet e a pedagogia - uma velha ideia muito atual. In: FORMOSINHO, J. O.; KISHIMOTO, T. M.; PINAZZA, M. Pedagogia(s) da infância: dialogando com o passado construindo o futuro. Porto Alegre: Artmed, 2007. p. $145-170$.

FERREIRA, S. Imaginação e linguagem no desenho da criança. Campinas: Papirus, 1998. 
FORMOSINHO, J. O.; KISHIMOTO, T. M.; PINAZZA, M. Pedagogia(s) da infância: dialogando com o passado construindo o futuro. Porto Alegre: Artmed, 2007.

FORTUNATI, A. A educação infantil como projeto da comunidade. Crianças, educadores e pais nos novos serviços para a infância e a família. Porto Alegre: Artmed, 2009.

GOBBI, M.; LEITE, M. I. O desenho da criança pequena: distintas abordagens na produção acadêmica em diálogo com a educação. Disponível em: <http://www.ced.ufsc.br/ nee0a6/ LEITE.pdf>. Acesso em: 27 nov. 2010.

LIMA, M. W. S. A cidade e a criança. São Paulo: Nobel, 1989.

MAY, R. A coragem de criar. Rio de Janeiro: Nova Fronteira, 1982.

RIZOLLI, M. Artista, cultura, linguagem. Campinas: Akademika, 2005.

ROUSSEAU, J. J. Emílio ou da educação. São Paulo: Martins Fontes, 2009.

SANTAELLA, L. (Arte) \& (cultura): equívoco do ecletismo. São Paulo: Cortez , 1995.

SANTOS, M. Espaço e método. São Paulo: Nobel, 1985.

SANTOS, M. O espaço e o cidadão. São Paulo: Nobel, 1987.

SILVEIRA, N. A concepção educacional de Herbert Read. Revista Brasileira de Estudos Pedagógicos, Brasília, jun. 1973.

Recebido em 22 de dezembro de 2010 e aprovado em 25 de março de 2011. 